\title{
The Two Faces of Uncertainty Avoidance: Attachment and Adaptation
}

\author{
David S. Baker and Kerry D. Carson \\ University of Louisiana at Lafayette
}

\begin{abstract}
The authors used a sample of 155 field sales personnel from the United States, Canada, United Kingdom, Australia, and New Zealand to examine attachment and adaptation as two ways of addressing individual uncertainty avoidance. Results suggest that both attachment and adaptation are used to reduce uncertainty avoidance in the workplace. Individuals low on uncertainty avoidance had no need to attach with their group or adapt to their environment. Those high on uncertainty avoidance used both techniques to deal with risk. Individuals reporting moderate levels of uncertainty avoidance primarily used adaptation rather than attachment to deal with risk.
\end{abstract}

\section{Introduction}

Geert Hostede's (1980) theoretical and empirical work on value development within national cultures has served as an important foundation for this field of international study (Triandis, 2004). Hofstede (1980) originally proposed a framework that consisted of four dimensions: uncertainty avoidance, individualism/collectivism, power distance, masculinity/femininity. He later added a fifth dimension, time orientation (Hofstede \& Bond, 1988).

Of particular interest in this study is the macro dimension of uncertainty avoidance measured at an individual level. Cultures high on uncertainty avoidance are risk adverse. Individuals in these cultures prefer stability in their lives and careers. They want their environment to be predictable. To foster compliance among their members, cultures high in uncertainty avoidance structure behavior through such mechanisms as laws, religion or customs. Vague situations are avoided in high uncertainty avoidance cultures, and group norms and rules reduce ambiguity. Individuals tend to attach themselves to the dominant cultural group and comply with its expectations (Hofstede, 1980).

However, there has been a suggestion in organizational research that rather than the more passive attachment to the dominant group, some cultures actively try to reduce uncertainty by controlling their future environment. For example, Schneider and DeMeyer (1991) suggested that managers in high uncertainty avoidance cultures are likely to engage in proactive behaviors in an attempt to adapt to a dynamic environment. Geletkanycz (1997) also found that executives who are high on uncertainty avoidance in their cultural background seek strategic solutions that respond to dynamic 
environments. That is, they engage in adaptation as a way of reduce risk. Because of this alternative way of adapting to uncertainty, Geletkanycz (1997) called for further research to examine the issue that not all individuals react to risk by adhering to the norm but rather adjust to position themselves in a safer position in the future.

Research has also identified that individuals high on uncertainty avoidance make choices for uncertain outcomes that involve gains (Ladbury \& Hinz, 2009). For example, individuals can be induced to volunteer for treatment in a randomly assigned process if they are offered monetary compensation for showing up (Harrison, Lau \& Rutstrom, 2009). An individual's income can also have an influence on uncertainty avoidance and outcomes. For example, Yang-Ming (2008) found that as income increases, individuals high on uncertainty avoidance were more willing to take risks.

The purpose of our research is to explore the use of both attachment and adaptation as ways of handling uncertainty. We are examining this at an individual level because uncertainty avoidance differs among individuals within similar cultures (Dwyer, Mesak, \& Hsu, 2005). An individual within a culture does not have to share the same viewpoint as the dominant majority and, in fact, there can be a considerable individual variability (Cross \& Madson, 1997). At the individual level, cultural values and dimensions can vary from high to low (Triandis, 1995). Following established examples of other researchers (e.g., Clugston, Howell, \& Dorfman, 2000; Dorfman \& Howell, 1988; Vitell, Paolillo \& Thomas, 2003), this study utilizes the macro concept of uncertainty avoidance analyzed at the individual level. Clugston Howell, and Dorfman (2000) noted that when examining differences within cultures it is required that researchers gauge individual perceptions of culture. Further, for this study it was important to use individual level measures as it was consistent with our methodology. According to Bockner and Hesketh (1994), independent measures used in cultural studies should be at the same level of analysis as the dependent variables.

\section{Uncertainty Avoidance and Attachment}

According to Hofstede (1980), the uncertainty avoidance dimension deals with the national culture's ability to tolerate ambiguity. Individuals in these high uncertainty avoidance cultures tend to be rigid and dogmatic. They are threatened by unknown situations. Life is perceived to have many risks, and the resultant stress needs to be lessened. So the cultures may rely upon such mechanisms as rules, customs, laws, and religion in pursuit of security.

High uncertainty avoidance results in many other risk reducing strategies. For example, companies operating in countries characterized by high uncertainty avoidance tend to hold more cash than companies in countries with low uncertainty avoidance. Cash was seen as a hedge against a potentially risky future (Ramirez \& Tadesse, 2009). On the other end of the continuum, a culture which is low in uncertainty avoidance is likely to be more innovative (Singh, 2006).

Individuals high on uncertainty avoidance also tend to exhibit more brand loyalty 
(Desmond, 2007; Lam, 2007). These individuals are suspicious of new products. They view new products less favorably than those in low uncertainty avoidance cultures and are less likely to purchase these products (Lee, Garbarino, \& Lerman, 2007). If there are problems with a service or product, those higher in uncertainty avoidance are less satisfied when their expectations are not met as compared to those lower in uncertainty avoidance (Reimann, Lunemann, \& Chase, 2008).

In addition to these types of behaviors, individuals in high uncertainty cultures try to control their present environment through strong identification with their group. This identification with the organization can be explained by social identity theory which suggests that individuals will classify themselves into social categories (Tajfel \& Turner, 1985). This classification provides order to the environment by allowing individuals to define themselves. It also provides them with the comfort of belonging to a group (Ashforth \& Mael, 1989). In countries characterized by high uncertainty avoidance, individuals see their culture and race as superior and desire to maintain traditions. They tend to be intolerant of opinions different from their own. When members feel threatened by uncertain situations, they handle this anxiety by looking for structure in their institutions so that the environment will be more predictable (Hofstede, 1980).

Because of the need to avoid risk, individuals who score high on uncertainty avoidance tend to have long tenure their organizations (Chew \& Putti, 1995). These individuals deal with their uncertainty by becoming committed to organizational goals and values and continuing in their relationship with the organization because of the potential loss in leaving (Clugston, Howell, \& Dorfman, 2000). However, it is an oversimplification to see the organization as the only workplace entity of concern. Most individuals spend their organizational lives in a work group, and this becomes their familiar surroundings. Therefore, when individuals make reference to their organization, they are also including the work group (van Knippenberg \& van Schie, 2000). Thus, in this study we are concerned about both the combination of work group and organizational attachment, which results in the following hypotheses.

Hypothesis 1: An individual's level of uncertainty avoidance is positively associated with attachment to the work group/organization.

\section{Uncertainty Avoidance and Adaptation}

In her research with business executives, Geletkanycz (1997) hypothesized that top managers whose background cultures were high on uncertainty avoidance would be uncomfortable with uncertainty. Because of their need for structure, she predicted that they would be resistant to change. They would avoid taking action to alter their situation. However, what she found in her research was that managers whose background cultures were high in uncertainty avoidance reduced their feeling of uncertainty by adapting to the environment. She surmised that in the dramatic changes related to technology and globalization, it was safer and less risky for these executives to adjust to the changing environment rather that inflexibly hanging on to what is known. 
Her research is consistent with the findings of Schneider and DeMeyer (1991) who suggested that Latin Europeans dealt with uncertainty avoidance by being proactive in dealing with environmental change which was seen as a threat or a crisis. When they compared a Latin European culture with high uncertainty avoidance to North American/Anglo cultures with low uncertainty avoidance, they found different responses between cultures. North American/Anglo cultures dealt with uncertainty avoidance through passive or risk-aversion responses while the Latin European culture dealt with uncertainty through adaptation. Schneider and DeMeyer's (1991) interpretation was that response is not a difference in uncertainty avoidance scores, but a culture's preferred response to avoiding uncertainty.

The cultural value of uncertainty avoidance influenced whether Irish firms were successful as compared to German firms (Rauch, Frese, \& Sonnentag, 2000). Ireland scores low on uncertainty avoidance in contrast to Germany which is high on the value. It was found that successful small business owners in Ireland did not plan. Rather, customers in that culture valued flexibility and quick solutions to problems. In contrast, German business owners were more successful when they did plan. It was proposed by these researchers that in such high uncertainty avoidance cultures, it was expected that individuals engage in careful planning to reduce risk by attempting to control future events. However, the results were more consistent with the interpretation made by Schneider and DeMeyer (1991) in that they found that planning is culturally appropriate, and this detailed planning resulted in a successful relationship with customers who also valued planning (Rauch, Frese, \& Sonnentag, 2000).

In our individual level of analysis, we wanted to identify individuals who are adaptive in their orientation. To do this, we focused on individuals who engage in proactive, achievement-oriented behaviors. Individuals with proactive behaviors recognize opportunities for meaningful change (Bateman \& Crant, 1993), and they persistently move to influence their environment so that they reach their goals (Crant, 2000). Those high on attributes associated with the proactive personality intensely network with others (Lambert, Eby, \& Reeves, 2006), are highly motivated to learn (Major, Turner, Fletcher, 2006), and engage in self-management behaviors regarding their career development (Chiaburu, Baker, \& Pitariu, 2006). Similarly, achievement-oriented individuals are adaptive in that they have a need to solve problems and conquer challenging tasks (McClelland, 1985). Achievement orientation is also positively linked to entrepreneurial behavior (DeMartino, Barbato, \& Jacques, 2006; Rhee \& White, 2007; Sebora, Lee, \& Sukasame, 2009; Utsch \& Rauch, 2000). Thus, adaptive behavior is viewed in this study as a combination of proactivity and achievement orientation.

Hypothesis 2: An individual's level of uncertainty avoidance is positively associated with the adaptive behaviors of proactivity and achievement orientation.

\section{Combinations of Attachment and Adaptation}

Attachment and adaptation represent different continua in that attachment is not the opposite of adaptation. Rather a possible opposite of attachment is aversion; while a 
possible opposite of adaptation is rigidity. Because these two constructs represent two different continua, they are not mutually exclusive. Therefore, it seems plausible that an individual could be both high in attachment and in adaptation, low on either, or high on one but not the other. While not dealing specifically with attachment and adaptation, a dual approach to high uncertainty avoidance is suggested in one study where managers: (1) played it safe by having higher margins of safety while (2) actively putting research efforts in order to avoid future tracking error (Beckmann, Menkhoff, \& Suto, 2008). Therefore, we can speculate that those highest in uncertainty avoidance would use both approaches while those lowest in uncertainty avoidance would use neither. Based on the preponderance of extant literature supporting attachment, we can further speculate that those individuals with moderate amounts of uncertainty avoidance will use attachment to lower their perceived risks. Therefore, we propose the following hypotheses:

Hypothesis 3A: Those individuals highest on uncertainty avoidance will both attach themselves to the work group/organization and adapt to their environment through proactivity and achievement-orientation.

Hypothesis 3B: Those individuals lowest on uncertainty avoidance neither attach themselves to the work group/organization nor adapt to their environment through proactivity and achievement-orientation.

Hypothesis 3C: Those individuals moderate on uncertainty avoidance attach themselves to the work group/organization.

\section{Method}

\section{Participants}

The sample population was comprised of 155 field sales personnel located in the United States $(n=70)$, Canada $(n=15)$, United Kingdom $(n=42)$, and Australia/New Zealand $(n=27)$ in a multinational firm operating in the business-to-business industrial sector. The lead author worked closely with top executives to receive permission to conduct the survey, and the respondents were assured of anonymity. Data was collected via internet survey methodology with consistently detailed instructions provided before and during the survey. Globally, a comprehensive five phase data collection procedure was designed and followed to insure the highest possible response rate. The five phases included global preliminary, regional preliminary, country preliminary, data collection, and management follow-up.

All layers of relevant corporate and field sales management were briefed individually prior to distribution of the survey instrument. Upon executive management approval and agreement to solicit participation from regional and country sales organization executives, regional heads were briefed on the study directly by the author. With region head agreement and their subsequent introduction, country unit executives were briefed by the author along with regional sales management. This personalized contacts 
facilitated a high 95\% response rate (Cook, Heath, \& Thompson, 2000). The high response rate was further supported by a short, visually friendly internet based survey (Deutskens, De Ruyter, Wetzels, \& Oosterveld, 2004) that was easily completed during the respondents normal work time spent on their company computer.

The average chronological age of the sample was 41 years, average organizational tenure was 14 years, and $41 \%$ held a college degree. Of the 147 respondents, six individuals exited the survey at various points and did not return to complete it. This constituted less than five percent of the sample responses, and incomplete responses were therefore removed from the final analysis. Following pre-determined data integrity testing procedures, we also identified three additional responses for removal due to insufficient time taken to complete the questionnaire. The final usable sample therefore totaled 138 responses.

\section{$\underline{\text { Measures }}$}

All measures were anchored on a seven point Likert scale from 1 (Strongly Disagree) to 7 (Strongly Agree). Uncertainty Avoidance was tapped using a scale consisting of five items (alpha coefficient $=.90$ ) developed by Dorfman and Howell (1988). Sample items include "Managers expect employees to closely follow instructions and procedures" and "Instructions for operations are important for employees on the job". Hofstede (1991) reports that the countries used in our research project score relatively low on uncertainty avoidance (e.g., Australia $=51$, Canada $=48, U K=35$, US $=46$ ). Our research deals with individual differences within North American and Anglo cultures, but as we noted earlier, there is a great deal of individual variation within cultures.

Attachment at work is a 12-item measure $(\alpha=.82)$ that combines two instruments, Organizational Identification and Work Group Loyalty, which were positively correlated at .359 ( $p$ <.01). Organizational Identification was gauged using a 6 -item scale $(\alpha=.753)$ developed by Mael and Ashforth (1992), and measurement has been found to be reliable in global settings (e.g., Mael \& Ashforth, 1995; van Knippenberg \& van Schie, 2000). Two sample items are "This company's successes are my successes" and "When someone praises my company, its feels like a personal compliment." Work group loyalty was tapped using a 6 -item scale $(\alpha=.83)$ developed by Dorfman and Howell (1988) to capture Hofstede's collectivism dimension at the work group level (Clugton, Howell, \& Dorfman, 2000). Sample items are "Being accepted by the member so your work group is very important" and "Managers should encourage group loyalty even if individual goals suffer."

Adaptation in the workplace is a 10 -item measure $(\alpha=.85)$ that combines a Proactive Behavior instrument and an Achievement Orientation instrument which were positively correlated at $.481(p<.01)$. A Proactive Behavior measure was originally developed by Bateman and Crant (1993), and a 6-item unidimensional measure was validated across cultures by Claes, Beheydt, \& Lemmens (2005). This abbreviated scale was used in the present study $(\alpha=.87)$. Two samples items include "I am always looking for better ways to do things" and "No matter what the odds, if I believe in something, I will make it 
happen." Achievement Orientation was tapped with a scale of 4 items $(\alpha=.66)$ based on Vitell, Paolillo, and Thomas (2003). Sample items include "It is important for me to have a job which has an opportunity for high earnings" and "It is important that I outperform others in my company."

\section{$\underline{\text { Analysis }}$}

Regression analysis was used to test the significance of the initial two hypotheses. In addition, correlations between Attachment and Uncertainty Avoidance and Adaptation and Uncertainty Avoidance were examined. Stepwise estimation provides an objective method for selecting variables that maximizes the prediction while employing the smallest number of variables (Hair, Black, Babin, Anderson, \& Tatham, 2006). This approach to estimation was chosen over forward addition elimination and backward elimination incremental methods due to its superior abilities to add or delete variables at each stage of the regression calculation. It should be noted that some authors such as Schmitt and Ployhart (1999) have identified limitations to stepwise regression related to bias and error when utilized with small sample sizes, as was the case in this study. However, this is more of a concern when there are a large number of regressors related to the sample size, which was not the case in this study.

The remaining hypotheses were examined by conducting a one-way analysis of variance. Analysis of Variance (ANOVA) is an important method in exploratory and confirmatory data analysis that is useful in when grouping predictor variables into batches. While linear regression analysis allowed us to test our general hyposthes $(\mathrm{H} 1$ and $\mathrm{H} 3$ ), ANOVA allowed us to test effectively display and visualize the hypothesized grouped predictor variables of Attachment and Adaptation through clearly differentiated cells and a visual plot (Gelman, 2005). To conduct this analysis, the Attachment and Adaptation measures were divided at their means. The sample was then grouped into one of four quadrants based on responses to Attachment and Adaptation measures (Group 1 = Low Attachment - Low Adaptation, $n=40$; Group 2 = Low Attachment High Adaptation, $\mathrm{n}=31$; Group 3 = High Attachment - Low Adaptation, $\mathrm{n}=33$; Group 4 $=$ High Attachment; High Adaptation, $\mathrm{n}=34$ ).

\section{Results}

Hypothesis 1 (an individual's level of uncertainty avoidance is positively associated with attachment to the work group/organization) and Hypothesis 2 (an individual's level of uncertainty avoidance is positively associated with the adaptive behaviors of proactivity and achievement orientation) were supported in that multiple regression analysis showed independent significance both for Attachment $(\beta=.247, p<.01)$ and Adaptation $(\beta=.347, p<.01)$. In support of these findings, the correlations between Attachment and Uncertainty Avoidance $(r=.31, \mathrm{p}<.01)$ and Adaptation and Uncertainty Avoidance $(r$ $=.41, p<.01$ ) were found to be significant. The correlation matrix is presented in Table 1.

Table 1. Adaptation, Attachment, and Uncertainty Avoidance 
Correlation Matrix $(\mathrm{N}=138)$

\begin{tabular}{|c|c|c|c|c|}
\hline & & Adaptation & Attachment & $\begin{array}{l}\text { Uncertainty } \\
\text { Avoidance }\end{array}$ \\
\hline Adaptation & $\begin{array}{l}\text { Pearson } \\
\text { Correlation }\end{array}$ & 1.00 & $.24^{* *}$ & $.41^{* *}$ \\
\hline Attachment & $\begin{array}{l}\text { Pearson } \\
\text { Correlation }\end{array}$ & $.24^{* *}$ & 1.00 & $.31^{* *}$ \\
\hline $\begin{array}{l}\text { Uncertainty } \\
\text { Avoidance }\end{array}$ & $\begin{array}{l}\text { Pearson } \\
\text { Correlation }\end{array}$ & $.41^{* *}$ & $.31^{* *}$ & 1.00 \\
\hline
\end{tabular}

${ }^{* *} . p \leq 0.01$

The means for the 4 cells with uncertainty avoidance as the dependent variable are (Group 1 = Low Attachment - Low Adaptation, mean = 4.78; Group 2 = Low Attachment - High Adaptation, mean = 5.27; Group $3=$ High Attachment - Low Adaptation, mean = 5.03; Group 4 = High Attachment - High Adaptation, mean = 5.87). The test on the linearly independent pairwise comparison was significant $(F=8.738, p<.01)$. The pairwise comparisons results on the dependent variable uncertainty avoidance are shown in Table 2.

Hypothesis 3A (individuals highest on uncertainty avoidance will both attach themselves to the work group/organization and adapt to their environment through proactivity and achievement-orientation) was a supported in that Group 4 (High Attachment - High Adaptation) is significantly different from all other groups (Group 1, $p<.01$; Group 2, p $<.05$; Group 3, $\mathrm{p}<.01$ ). Hypothesis 2B (individuals lowest on uncertainty avoidance neither attach themselves to the work group/organization nor adapt to their environment through pro-activity and achievement-orientation) also was supported in that Group 1 (Low Attachment - Low Adaptation) is significantly different $(p<.05)$ from Group 2 (Low Attachment - High Adaptation) and Group 4 (High Attachment - High Adaptation). However, Hypothesis $3 \mathrm{C}$ (individuals moderate on uncertainty avoidance attach themselves to the work group/organization) was not supported in that Group 3 (High Attachment - Low Adaptation) was not significantly different from Group 1 (Low Attachment - Low Adaptation). Rather, it was Group 2 (Low Attachment - High Adaptation) that was different from Group 1 (Low Attachment - Low Adaptation) suggesting that in this sample, individuals with a moderate level of uncertainty used adaptation to reduce risk. A plot of the four groups on uncertainty avoidance is shown in Figure 1. 
Table 2. Attachment and Adaptation Pairwise Comparisons

Group 1= Low Attachment, Low Adaptation

Group 2= Low Attachment, High Adaptation

Group 3= High Attachment, Low Adaptation

Group 4= High Attachment, High Adaptation

Dependent Variable: Uncertainty Avoidance

(I)

(J)

Mean

Group Group Difference

\begin{tabular}{|c|c|c|c|c|}
\hline Variable & Variable & $(\mathrm{I}-\mathrm{J})$ & Std. Error & Sig. \\
\hline \multirow[t]{3}{*}{1} & 2 & $-49^{x-}$ & .23 & .03 \\
\hline & 3 & -.25 & .22 & .26 \\
\hline & 4 & $-1.09^{*}$ & .22 & .00 \\
\hline \multirow[t]{3}{*}{2} & 1 & $.49^{*}$ & .23 & .03 \\
\hline & 3 & .24 & .24 & .31 \\
\hline & 4 & $-.60^{*}$ & .24 & .01 \\
\hline \multirow[t]{3}{*}{3} & 1 & .25 & .22 & .26 \\
\hline & 2 & -.24 & .24 & .31 \\
\hline & 4 & $-.84^{*}$ & .23 & .00 \\
\hline \multirow[t]{3}{*}{4} & 1 & $1.09^{*}$ & .22 & .00 \\
\hline & 2 & $.60^{*}$ & .24 & .01 \\
\hline & 3 & $.84^{*}$ & .23 & .00 \\
\hline
\end{tabular}

Based on estimated marginal means

* The mean difference is significant at the .05 level.

\section{Discussion}

Much of the extant literature suggests that individuals respond to uncertainty by attaching themselves to the dominant groups in their culture and modeling behavior after group norms. This approach reduces the ambiguity in situations. However, there were a few studies suggesting that there is a second approach to uncertainty avoidance. That is, some individuals reduce feelings of uncertainty by adapting to their environment. For these individuals, it may be less risky to adjust to a dynamic environment rather than rigidly hanging onto the present. This is what was found in the present study. In fact, as indicated by the regression analysis between attachment and uncertainty avoidance $(\beta=.247, p<.01)$ and between adaptation and uncertainty avoidance $(\beta=.347, p<.01)$, the second approach appears to be the preferred strategy by these individuals who were engaged in business-to-business sales in an international setting. 


\section{Figure 1}

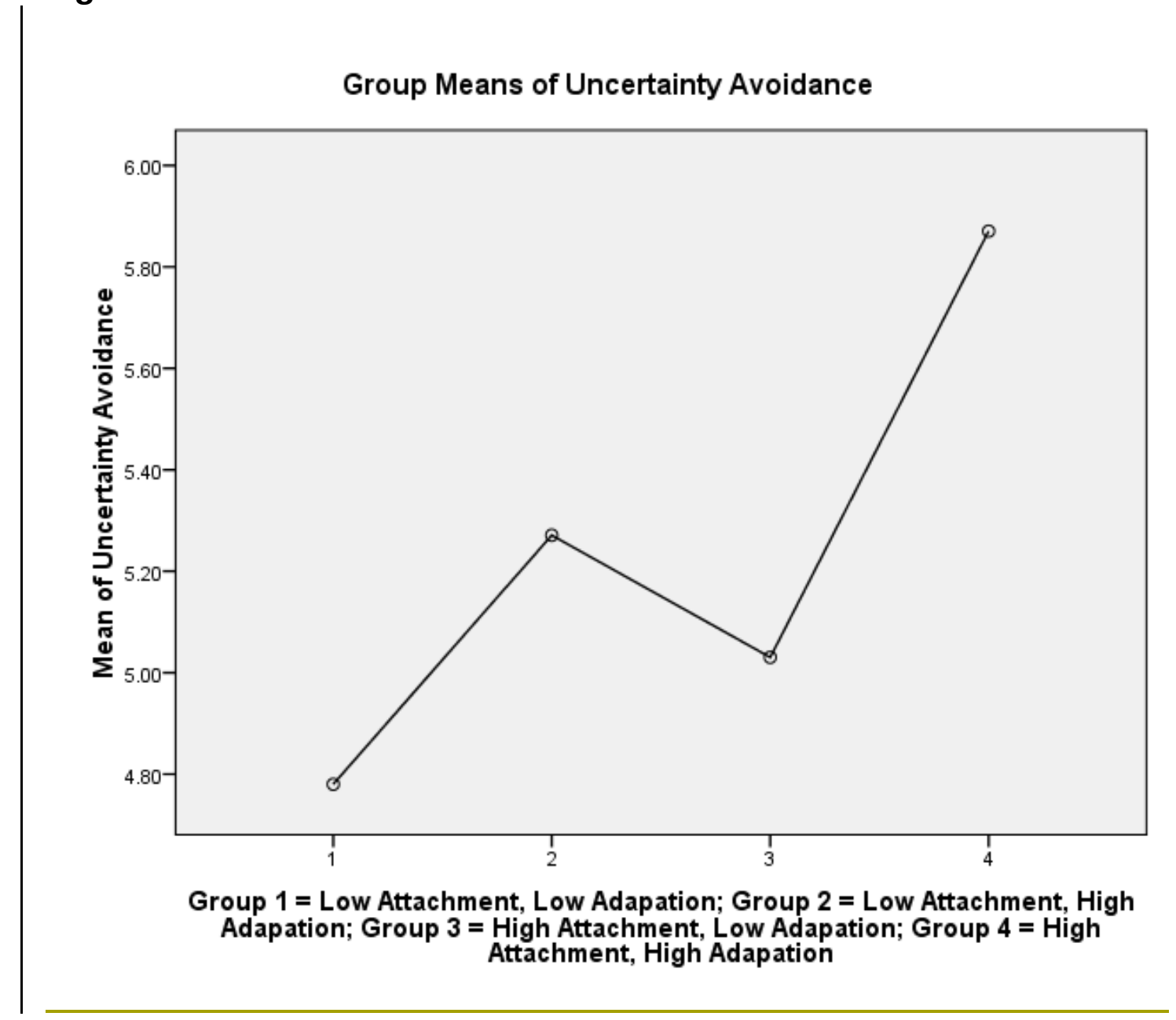

For those with the highest uncertainty avoidance, individuals use both methods for reducing risk (see Figure 1) by attaching to their work group/organization and proactively adapting to the future environment. Those with the lowest uncertainty avoidance have neither the need to attach or adapt. However, those with moderately high uncertainty avoidance appeared to prefer adaptation over attachment.

The individual's response to uncertainty has practical implications in the workplace. For example, when formulating strategy for the organization, there may be situations where adaptation is the appropriate response and other environments where attachment is the preferred response. For example, in a "blue ocean" defined by Kim and Mauborgne (2005) as markets not in existence today, and adaptation strategic style would be appropriate. Here, the manager needs to be very flexible and innovative because the organization will be creating demand in an untapped market. However, sometimes a "red ocean" strategy is relevant (Kim \& Mauborgne 2009). Here, the environment is very competitive and the manager stays attached to the traditional business model following a strategy of differentiation or low cost. In complex and diversified companies, both adaptation and attachment are relevant. 
While, these findings suggest an important avenue for uncertainty avoidance research, the nature of the sample in this study must be kept in mind. High achievement-oriented individuals are attracted to sales, and the adaptation method of dealing with uncertainty may be the natural preference for these individuals. Also, the sample consists on North America and Anglo cultures which may prefer this approach to risk. However, it should be pointed out that this notion is in contrast to Schneider and DeMeyer (1991) who suggested these cultures prefer to manage uncertainty avoidance through attachment or risk-aversion responses. Because individuals from these cultures would theoretically prefer adaptive techniques, this study is therefore not generalizeable beyond the study population. While it may be that both attachment and adaptive techniques would be used under the higher conditions of uncertainty and neither techniques would be needed in lower conditions, it is likely that most individuals from these cultures sampled would use attachment rather than adaptation as the preferred means in conditions of moderate uncertainty. Therefore, while interesting in its potential for further generalizeability through future cross-validation studies, this study therefore should be limited to its own population and not generalized to larger, more culturally diverse populations which were not represented in the sample.

Hofstede's research establishing the Uncertainty Avoidance dimension was on the national level of analysis though subsequent research has also established the crosscultural importance and validity of examining this dimension at the individual level of analysis (Clugston, Howell, \& Dorfman, 2000; Dorfman \& Howell, 1988). It would be possible to examine our dataset at a national level if the sample size for each country was greater. Our data contained field sales respondents from five different countries and their individual nationality can be included as a variable (e.g. a dummy variable for each country). However, this would necessitate collection of additional data from countries such as Canada (e.g., Canada had only 15 responses) and New Zealand which is not possible in this study. Future research that undertakes broadening the sample for a greater range of uncertainty avoidance scores between countries would be an interesting extension of this study and would be more consistent and comparable to Hofstede's original national identity thesis.

While we report here that individuals rationally choose to attach and/or adapt to their environment, an individual's strategy to manage risk and uncertainty is probably more complex than this. Most formal theories of decision making, such as prospect theory (Kahneman \& Tversky, 1979), assumes that individuals make a rational choice based on probability. However, many times individuals use intuition or non-probabilistic rules to respond to uncertainty (Rottenstreich \& Kivetz, 2006). While on one hand, an individual's approach to uncertainty avoidance may be quite rational and cognitive; on the other hand, an individual may use intuition to manage the future. This intuitive response may lead to less rational strategies. Further, a strong emotional response to a situation may also lead to avoidance (Zinn, 2008). Other interesting research questions include whether attachment and adaptive strategies diminish as income increases and if individual differences such as gender influence how individuals deal with uncertainty. All this suggests that there is much potentially fruitful research yet to be conducted in the 
area of uncertainty avoidance.

\section{References}

Ashforth, B. E., \& Mael, F. (1989). Social identification theory and the organization. Academy of Management Review, 14(1), 20-39.

Bateman, T. S., \& Crant, J. M. (1993). The proactive component of organizational behavior: A measure and correlates. Journal of Organizational Behavior, 14, 103118.

Beckmann, D., Menkhoff, L., \& Suto, M. (2008). Does culture influence asset manager's views and behavior? Journal of Economic Behavior \& Organization, 67(3/4), 624.

Bockner, S., \& Hesketh, B. (1994). Power distance, individualism/collectivism, and jobrelated attitudes in a culturally diverse work group. Journal of Cross-Cultural Psychology, 25(2), 233-257.

Chiaburu, D. S., Baker, V. L., \& Pitariu, A. H. (2006). Beyond being proactive: What(else) matters for career self-management behaviors? Career Development International, 11(7), 619-632.

Chew, I., \& Putti, J. (1995). Relationship on work-related values of Singaporean and Japanese managers in Singapore. Human Relations, 48, 1149-1170.

Claes, R., Beheydt, C., \& Lemmens, B. (2005). Undimensionality of abbreviated proactive personality scales across cultures. Applied Psychology: An International Review, 54(4), 476-489.

Clugston, M., Howell, J. P, \& Dorfman, P. W. (2000). Does cultural socialization predict multiple bases and foci of commitment? Journal of Management, 26(1), 5-30.

Cook, C., Heath, F., \& Thompson, R. (2000). A Meta analysis of response rates in web or Internet based surveys. Educational \& Psychological Measurement, 60(6), 821-836.

Crant, J. M. (2000). Proactive behavior in organizations. Journal of Management, 26(3), 435-462.

Cross, S. E., \& Madson, L. (1997). Models of the self: Self-construals and gender. Psychological Bulletin, 122, 33-37.

DeMartino, R., Barbato, R., \& Jacques, P. H. (2006). Exploring the career/achievement and personal life orientation differences between entrepreneurs and nonentrepreneurs: The impact of sex and dependents. Journal of Small Business Management, 44(3), 350-368.

Desmond, L. (2007). Cultural influence on proneness to brand loyalty. Journal of International Consumer Marketing, 19(3), 7-21.

Deutskens, E., De Ruyter, K., Wetzels, M., \& Oosterveld, P. (2004). Response Rate and Response Quality of Internet-Based Surveys: An Experimental Study. Marketing Letters, 15(1), 21-36.

Dorfman, P. W., \& Howell, J. P, (1988). Dimensions of national culture and effective leadership patterns: Hofstede revisited. Advances in International Comparative Management, 3, 127-150.

Dwyer, S., Mesak, H., \& Hsu, M. (2005). An exploratory examination of the influence of national culture on cross-national product diffusion. Journal of International Marketing, 13(2), 1-27. 
Geletkanycz, M. A. (1997). The salience of 'culture's consequences': The effects of cultural values on top executive commitment to the status quo. Strategic Management Journal, 18(8), 615-634.

Hair Jr., J. F., W. C. Black, Babin, B., Anderson, R. E., \& Tatham, R. L. (Eds.) (2006). Multivariate Data Analysis. Upper Saddle River, NJ: Pearson Prentice Hall.

Harrison, G. W., Morten, L., \& Rutstrom, E. (2009). Risk attitudes, randomization to treatment, and self-selection into experiments. Journal of Economic Behavior \& Organization, 70(3), 498-507.

Hofstede, G. (1980). Culture's consequences: International differences in work-related values. Newbury Park, CA: Sage.

Hofstede, G. (1991). Cultures and organizations: Software of the mind. London: McGraw-Hill.

Hofstede, G., \& Bond, M. H. (1988). The Confucius connection: From cultural roots to economic growth. Organizational Dynamics, 16, 5-21.

Kahneman, D., \& Tversky, A. (1979). Prospect theory: An analysis of decision under risk. Econometrica, 47, 263-292.

Kim, W. C., \& Mauborgne, R. (2005). Blue ocean strategy: From theory to practice. California Management Review, 47(3), 105-121.

Kim, W. C., \& Mauborgne, R. (2009). How strategy shapes structure. Harvard Business Review, 87(12), 73-80

Ladbury, J., \& Hinsz, V. B. (2009). Uncertainty avoidance influences choices for potential gains but not losses. Current Psychology, 28(3), 187-193.

Lam, D. (2007). Cultural influence on proneness to brand loyalty. Journal of International Consumer Marketing, 19(3), 7-21.

Lambert, T. A., Eby, L. T., \& Reeves, M. P. (2006). Predictors of networking intensity and network quality among white-collar job seekers. Journal of Career Development, 32(4), 351-365.

Lee, J. A., Garbarino, E., \& Lerman, D. (2007). How cultural differences in uncertainty avoidance affect product perceptions. International Marketing Review, 24(3), 330-349.

Mael, F. A., \& Ashforth, B. E. (1992). Alumni and their alma mater: A partial test of the reformulated model of organizational identification. Journal of Organizational Behavior, 13, 103-123.

Mael, F. A., \& Ashforth, B. E. (1995). Loyal from day one: Biodata, organizational identification, and turnover among newcomers. Personnel Psychology. 48, 309333.

Major, D. A., Turner, J. E., \& Fletcher, T. D. (2006). Linking proactive personality and the big five to motivation to learn and development activity. Journal of Applied Psychology, 91(4), 927-935.

McClelland, D. C. (1985). Human motivation. Glenview, IL: Scott, Foresman.

Ramirez, A., \& Tadesse, S. (2009). Corporate cash holdings, uncertainty avoidance, and the multinationality of firms. International Business Review, 18(4), 387-403.

Rauch, A., Frese, M., \& Sonnentag, S. (2000). Cultural differences in planning/success relationships: A comparison of small enterprises in Ireland, West Germany, and East Germany. Journal of Small Business Management, 38(4), 28-41.

Reimann, M., Lunemann, U. F., \& Chase, R. B. (2008). Uncertainty as a moderator of 
the relationship between perceived service quality and customer satisfaction. Journal of Service Research, 11(2), 63-73.

Rhree, K. S., \& White, R. J. (2007). The emotional intelligence of entrepreneurs. Journal of Small Business \& Entrepreneurship, 20(4), 409-425.

Rottenstreich, Y., \& Kivetz, R. (2006). On decision making without likelihood judgment. Organizational Behavior and Human Decision Processes, 101(1), 74-88.

Schmitt, N., \& Ployhart, R. (1999). Estimates of cross-validity for stepwise regression and with predictor selection. Journal of Applied Psychology, 84(1), 50-57.

Schneider, S. C., \& DeMeyer, A. (1991). Interpreting and responding to strategic issues: The impact of national culture. Strategic Management Journal, 12(4), 307-320.

Sebora, T. C., Lee, S. M., \& Sukasame, N. (2009). Critical success factors for 3commerce entrepreneurship: An empirical study of Thailand. Small Business Economics, 32(3), 303-316.

Singh, S. (2006). Cultural differences in, and influences on, consumers' propensity to adopt innovations. International Marketing Review, 23(2), 173-191.

Tajfel, H., \& Turner, J. C. (1985). The social identity theory of intergroup behavior. In S. Worchel \& W. G. Austin (Eds.), Psychology of intergroup relations $\left(2^{\text {nd }}\right.$ ed., pp. 724). Chicago: Nelson-Hall.

Triandis, H. C. (1995). Individualism and collectivism. Boulder, CO: Westview Press.

Triandis, H. C. (2004). The many dimensions of culture. Academy of Management Executive, 18(1), 88-93.

Utsch, A., \& Rauch, A. (2000). Innovativeness and initative as mediators between achievement orientation and venture performance. European Journal of Work \& Organizational Psychology, 9(1), 45-62.

van Knippenberg, D., \& van Schie, E. C. M. (2000). Foci and correlates of organizational commitment. Journal of Occupational \& Organizational Psychology, 73, 137-147.

Vitell, S. J., Paolillo, J. G. P., \& Thomas, J. L. (2003). The perceived role of ethics and social responsibility: A study of marketing professionals. Business Ethics Quarterly, 13(1), 63-86.

Yang-Ming, C. (2008). Risk avoidance and risk taking under uncertainty. A graphical analysis. American Economist, 52(1), 73-85.

Zinn, J. O. (2008). Heading for the unknown: Everyday strategies for managing risk and uncertainty. Health, Risk, \& Society, 10(5), 429-450. 